\title{
Expansões socioeconômicas, lógicas de salvaguarda e implicações a preservação de sítios arqueológicos no Amazonas - Amazônia Central
}

\section{Socioeconomic expansions, safeguard logic and implications for the preservation of archaeological sites in the Amazon - Central Amazon}

DOI: $10.46814 /$ lajdv3n5-027

Recebimento dos originais: 01/05/2021

Aceitação para publicação: 31/06/2021

\section{Benedito Walderlino de Souza da Silva}

Doutorando em Arqueologia pela Universidade de Coimbra

Inside Consultoria Científica - Departamento de Arqueologia

End.: Tv. Lomas Valentina, no 2625, sala 302, Marco, CEP.: 66095-770, Belém, Pará, Brasil.

E-mail: beneditowsouzas@gmail.com

\section{Wagner Fernando da Veiga e Silva}

Especialista em Arqueologia pela Universidade Federal do Pará

Inside Consultoria Científica - Departamento de Arqueologia

End.: Tv. Lomas Valentina, $\mathrm{n}^{\circ}$ 2625, sala 302, Marco, CEP.: 66095-770, Belém, Pará, Brasil.

E-mail: wagnerveiga@yahoo.com.br

\section{Anna Barbara Cardoso da Silva}

Mestre em Antropologia com área de concentração em Arqueologia pela Universidade Federal do Pará

Inside Consultoria Científica - Departamento de Arqueologia

End.: Tv. Lomas Valentina, nº 2625, sala 302, Marco, CEP.: 66095-770, Belém, Pará, Brasil.

E-mail: annabarao@gmail.com

\section{Kelton Lima Monteiro Mendes}

Mestre em Antropologia com área de concentração em Arqueologia pela Universidade Federal do Pará

Inside Consultoria Científica - Departamento de Arqueologia

End.: Tv. Lomas Valentina, no 2625, sala 302, Marco, CEP.: 66095-770, Belém, Pará, Brasil.

E-mail: keltonmendes@gmail.com

\section{RESUMO}

As discussões sobre o estado de preservação e possibilidades de impactos a sítios arqueológicos na arqueologia brasileira têm sido um tema recorrente e importante para moldar as ações de instituições de salvaguarda e pesquisadores da área. Especialmente a partir da década de 1960, vários estudos têm sido realizados sobre esse tema na intenção de diagnosticar e, quando possível, agir sobre as questões de conservação. Independentemente do ambiente e tipo de sítios arqueológicos que sejam objeto dessas preocupações, tem se mostrado necessário levar em consideração a ocupação humana recente como um dos principais fatores de interferência sobre os sítios. A partir do levantamento realizado em 100 sítios arqueológicos localizados nos municípios de Manaus e Iranduba, Estado do Amazonas, buscamos contribuir com esta questão. Para tal, partimos do princípio que é imprescindível considerar a relação de comunidades contemporâneas com objetos arqueológicos a partir não só das estratégias de ocupação e uso do espaço que processam sobre áreas com sítios arqueológicos, como também 
ponderar a influência das lógicas de salvaguarda cultural que se utilizam ao longo da formação de suas identidades culturais e memória social.

Palavras-chave: Salvaguarda Cultural; Arqueologia Amazônica; Recadastramento de Sítios Arqueológicos.

\begin{abstract}
Discussions about the state of preservation and possibilities of impacts on archeological sites in Brazilian archeology have been a recurrent and important theme to shape the actions of safeguard institutions and researchers in the area. Especially since the 1960s, several studies have been carried out on this topic with the intention of diagnosing and, when possible, acting on conservation issues. Regardless of the environment and type of archaeological sites that are the object of these concerns, it has proved necessary to take into account recent human occupation as one of the main factors interfering with the sites. Based on the survey carried out in 100 archaeological sites located in the cities of Manaus and Iranduba, State of Amazonas, we seek to contribute to this issue. To this end, we assume that it is essential to consider the relationship of contemporary communities with archaeological objects from not only the occupation and use of space strategies that process over areas with archaeological sites, but also to consider the influence of cultural safeguard logics that are they use throughout the formation of their cultural identities and social memory.
\end{abstract}

Keywords: Cultural Safeguard; Amazon Archeology; Re-registration of Archaeological Sites.

\title{
1 INTRODUÇÃO
}

Como atestam os resultados de pesquisas arqueológicas realizadas na Amazônia Central, especialmente as concentradas na confluência dos rios Negro e Amazonas, desde a segunda metade do século XX, culminando na identificação de vários sítios arqueológicos; o território do Estado do Amazonas constitui um dos importantes espaços de pesquisa para a Arqueologia da América do Sul, apresentando ocupações humanas que remontam a 9000 AP, responsáveis por uma diversidade cultural considerável.

Ciente da alta concentração de sítios nos municípios amazonense de Manaus e Iranduba, bem como de eventos de depredação resultantes de ações antrópicos, entre 2018 e 2021, o Instituto do Patrimônio Histórico e Artístico Nacional (Iphan) resolve desenvolver o "Programa de Recadastramento de Sítios Arqueológicos nos Municípios de Manaus e Iranduba, no Estado do Amazonas", incumbindo a Inside Consultoria Científica a responsabilidade pela execução de ações previstas no programa.Tendo como base a realidade identificada em 100 sítios arqueológicos distribuídos ao longo de ambientes rurais e urbanos dos municípios, este artigo discute os resultados do programa em associação a crescente preocupação dos atores envolvidos nas pesquisas arqueológicas no Brasil quanto ao estado de preservação de sítios arqueológico, sobretudo diante da presença de comunidades atuais habitando nos espaços físicos onde foram identificados. 
Assim, avaliamos as particularidades e resultados das diferentes expansões socioeconômicas responsáveis pela densidade demográfica do que, hoje, constitui os territórios de Iranduba e Manaus e os resultados destas sobre o estado de preservação dos sítios arqueológicos já identificados nesses municípios, ao longo de mais de cinco décadas de pesquisas arqueológicas. Ainda, abordaremos os contextos sociais brasileiros que culminam na existência de ações de preservação cultural que alimentam processos de acautelamento de bens culturais, tal qual a conjuntura que resulta nas ações de salvaguarda como as do programa de recadastramento dos sítios. Dessa forma, avaliando como esse caso pode contribuir na ponderação dos resultados de políticas de preservação e valorização cultural diante tanto da existência conjunta de objetos que configuram registros de ocupações humanas précoloniais e ocupações humanas contemporâneas, quanto do fato da condição de bens da União, dotados de proteção legal, que estes objetos dispõem.

\section{LÓGICAS DE SALVAGUARDA E PRESERVAÇÃO DO PATRIMÔNIO CULTURAL NO BRASIL}

Atingindo uma extensão territorial abrangendo uma área de aproximadamente $14.000 \mathrm{~km}^{2}$, além de fomentar a identificação de novos sítios arqueológicos, o programa de recadastramento realizado na Amazônia Central por Iphan e Inside, entre 2000 e 2021, visou atualizar os dados de localização e caracterização desse tipo de bem cultural da região (SILVA et. al. 2020). Ainda, garantir atualização de dados constantes no Cadastro Nacional de Sítios Arqueológicos (CNSA), especialmente para o caso de sítios que, por ocasião de sua identificação, não tenham sido georreferenciados ou que os registros demandem mais dados.

Enquanto instituição pública responsável pelo gerenciamento das políticas federais de salvaguarda de bens culturais no Brasil, o Iphan se valerá dos resultados produzidos pelo programa para alimentar os dados constantes no seu Sistema Integrado de Conhecimento e Gestão e, por consequência, planejar ações de salvaguarda adequadas a realidade particular de sítios arqueológicos em relação a sua atual condição de preservação em Iranduba e Manaus.

Preocupações como estas, envolvendo órgãos de administração pública atuantes em questões relacionadas a memória e a preservação do patrimônio cultural, nasceram na Europa do final do século XVIII e chegaram ao país no fim do século XIX, associadas a necessidade de formação de uma identidade cultural nacional para subsidiar a nova condição do Brasil de Estado Nação do mundo moderno. A formação de uma identidade para a nação brasileira, contudo, é um projeto marcado por muitos contratempos. Alguns dos principais problemas que geram esses entraves concentram-se no âmbito do gerenciamento da conservação do patrimônio. Derivam dele, por exemplo, embates ideológicos e políticos no campo do que deve ser preservado, assim como quais estratégias devem ser 
usadas para garantir tal preservação diante de intervenções antrópicas alheias as políticas de salvaguarda.

Acompanhando modelos da Europa do final do século XVIII, no Brasil, estas questões também foram parte da preocupação dos intelectuais do país ao se aterem a interpretar a história humana visando compreender particularidades de seus costumes para perceber o desenvolvimento dos povos no contexto das condições materiais em que se desenvolviam; ou seja, constatar a variedade de modos de vida entre povos e nações, ao mesmo tempo em que criavam imagens para moldar a identidade de uma nação com populações naturais colonizadas e imigrantes de vários lugares (SANTOS, 1985).

Em nível federal, a materialização desses debates ficou a cargo Sphan, criado em 1937 como Serviço do Patrimônio Artístico e Histórico Nacional (BRASIL, 1937a), hoje, instituto (Iphan). Em sua missão de órgão público gestor de ações de salvaguarda do patrimônio cultural brasileiro, especialmente a partir de 1960, o Iphan tem atuado fortemente na preservação e valorização de bens arqueológicos. Mas, como bem observa Funari (2001), as ações de preservação levadas a cargo pelo instituto estiveram voltadas ideologicamente à memória da colonização portuguesa, dada à ampla valorização e ênfase de suas ações sobre monumentos com traços arquitetônicos desse período da história brasileira.

Por conta disso, até o início da década de 2000, pouca efetividade foi engendrada para a proteção de bens culturais de outros grupos formadores da sociedade brasileira, mesmo os mais expoentes como os indígenas e negros. Realidade que demandou do Iphan a necessidade de pensar instrumentos de salvaguarda específicos para mudar esse quadro. Desdobramentos positivos nesse sentido resultaram na criação do Registro, instrumento de salvaguarda voltado a bens cultuais imateriais, regulamentado pelo Decreto n. 3.551 de 2000 (BRASIL, 2000), resultando na atribuição do título de Patrimônio Cultural Imaterial do Brasil a um bem cultural que é alvo de suas ações.

Além deste, inda há o Inventário Nacional de Diversidade Linguística (INRC), regulamentado pelo Decreto n. 7.387 de 2010 (BRASIL, 2010) e a Chancela da Paisagem Cultural Brasileira regulamentada pela Portaria Iphan n. 127 de 2009 (IPHAN, 2009). O primeiro tem como foco de ação as línguas portadoras de referência à identidade, à ação e à memória dos diferentes grupos formadores da sociedade brasileira. Já o segundo visa preservar porções do território nacional representativas de diferentes processos de interação do homem com o meio natural, nas quais foram impressas marcas culturais dessa relação.

Embora surgidos apenas na década de 2000, estes instrumentos de salvaguarda de bens culturais representam uma nova fase da atuação do Iphan nas questões de salvaguarda da cultura brasileira, atentando a necessidade de torná-la mais abrangente em relação aos bens culturais alvos de políticas de acautelamento. Antes do uso desses instrumentos imperavam as políticas de preservação e 
valorização cultural pautadas no Tombamento. Este instituído por meio do Decreto n. 25 de 1937 (BRASIL, 1937b), tendo como alvo de ação obras de arte e sítios históricos urbanos, portanto, voltando-se a vertente material do patrimônio e, como mencionando anteriormente, concentrando forças nos registros materiais de cultura resultados da colonização portuguesa no Brasil.

Também é importante referendar que, nas esferas e agendas da administração pública brasileira que serviram e servem de suporte a atuação do instituto, é notório certa tendência a relegar a segundo plano o setor da cultura. Prova disso, são os próprios percalços enfrentados para a criação e atuação inicial do órgão (SILVA, 2016). Surgidas em meio a essas dificuldades, as políticas resultadas da maior atenção a vertente material do patrimônio evidenciam um grande escamoteamento das relações antrópicas associadas a bens culturais arquitetônicos e significações sociais que surgem dessa relação.

Enquanto bens culturais, em sua maioria, parte do registro de modos de vida de comunidades indígenas do período pré-colonial brasileiro, sítios arqueológicos não ficaram imunes a essas conjunturas. Apartados das lógicas de salvaguarda atreladas a arquitetura colonial, desde a década de 1930, relatos de danos físicos decorrentes de intervenção humana sobre sítios já vinham sendo denunciados. Torres (1938) alertou o estado preocupante de conservação das "jazidas arqueológicas" brasileiras e os contextos físicos de destruição. Três eram as principais ordens de danos físicos que observou estarem contribuindo para essa situação: danos causados pelo tempo, pela "ignorância do povo" e pelos interesses econômicos imediatos.

Destes, os mais danosos tradicionalmente foram os interesses econômicos imediatos, dado resultarem na intensificação de atividades dessa natureza em áreas de sítios (LIMA, 2009), conforme denunciavam figuras expoentes que atuaram na salvaguarda de bens arqueológicos brasileiros desde a década de 1950, como Loureiro Fernandes no Centro de Estudos e Pesquisas Arqueológicas (CEPA) da Universidade Federal do Paraná (UFPR), Castro Farias no Museu Nacional da Universidade Federal do Rio de Janeiro (UFRJ) e Paulo Duarte no engajamento para a criação da Universidade de São Paulo (USP) e o Sphan.

Do trabalho conjunto desses atores do campo científico e da relação política junto a figuras expoentes do poder público, como o presidente Juscelino Kubitschek, o primeiro instrumento federal de salvaguarda de bens arqueológicos foi promulgado, a Lei n. 3.924 de 26 de julho de 1961 (BRASIL, 1961). A partir da lei, outros instrumentos de acautelamento de bens arqueológicos foram criados, demonstrando evoluções no que concerne a preocupação do Estado em relação a salvaguarda desses bens. No artigo 216 da Constituição de 1988 (BRASIL, 1988), por exemplo, objetos arqueológicos são referendados como bens da União, devendo o Estado e a sociedade serem agentes ativos de sua preservação e valorização. 
Nos projetos desenvolvimentistas posteriores a esses avanços no campo da salvaguarda de bens arqueológicos, uma das respostas dadas pelo Estado para coibir depredações desses bens se deu com a promulgação de leis ambientais e patrimoniais mais contundentes. Dentre estas, destacam-se a Resolução Conama n. 01 de 1986 (CONAMA, 1986) e a Resolução Conama n. 237 de 1997 (CONAMA, 1997) no campo da preservação ambiental fazendo uma convergência com a Portaria Sphan n. 07 de 1988 (SPHAN, 1988), a Portaria Iphan n. 230 de 2002 (IPHAN, 2002) e, mais recentemente, a Instrução Normativa (IN) Iphan n. 1 de 2015 (IPHAN, 2015) no campo da salvaguarda de bens arqueológicos.

Conforme observa (SILVA, 2021), um dos benefícios dessa combinação foi proporcionar novas parcerias entre arqueólogos e instituições públicas ou privadas atuantes no campo da salvaguarda cultural de bens arqueológicos. A presença da Arqueologia Preventiva (comumente denominada de Arqueologia por Contrato) atuando junto a programas de avaliação de impacto ambiental de empreendimentos tem favorecido o antecipado diagnóstico, avaliação e salvamento de bens arqueológicos nas áreas de abrangência desses empreendimentos. Mesmo que tomada como exígua, essa situação representa a materialização do alcance da gestão cultura participativa no campo preservação e valorização de bens culturais no Brasil pregada pelo artigo 216 de sua Constituição de 1988.

Embora sejam alvos de duras críticas, em muitos casos, de figuras expoentes da pesquisa acadêmica, mas com raras experiências no campo da arqueologia preventiva para lhes dar condições de avaliar adequadamente seus alcances positivos e negativos, o tempo tem mostrado que a Arqueologia por Contrato tem seu valor. Em absoluto, desde que respeitadas as leis trabalhistas e os direitos humanos, não é o regime de trabalho que determina o caráter, qualidade técnica e responsabilidade de qualquer profissional. Com a arqueologia, não é diferente. A Arqueologia Preventiva tem prestado importante contribuição para a construção de soluções que garantam a inserção de dados relativos a bens arqueológicos na memória nacional, em lugar de sua perda total (CALDARELLI, 2005). Por exemplo, quando são destruídos sem nenhum estudo ao estarem situados em lugares remotos e não alcançados pelos parcos recursos públicos destinados a medidas protecionistas.

Apesar desses lugares concentrem a maior parte dos projetos desenvolvimentistas e acarretem um acelerado processo de expansão da ocupação sobre o território brasileiro, ao passo que contribuem com modificações na paisagem de várias regiões do país e, por sua vez, com possibilidades de degradação de sítios arqueológicos (FUNARI, 2001), resta o consolo de que estão submetidos aos licenciamentos e controles necessários a depredação de bens naturais e culturais. Contudo, áreas rurais também são marcadas por atividades antrópicas não gerenciadas pelo Estado e seus regimes de 
legislação ambiental e patrimonial, embora também tenham alto potencial de impacto sobre os bens que elas devem acautelar.

Como discutido a seguir, este é o caso dos sítios arqueológicos contemplados com o "Programa de Recadastramento de Sítios Arqueológicos nos Municípios de Manaus e Iranduba, no Estado do Amazonas". Como mencionamos anteriormente, estes municípios estão situados em uma das áreas mais importantes para as discussões sobre a ocupação humana pré-colonial da América do Sul, a Amazônia Central. Nas bacias hidrografias dos rios Negro e Amazonas, encontram-se sítios arqueológicos com cultura material e datações que têm movimentado as discussões da comunidade científica sobre esse tema. Ainda assim, o programa demonstrou vários casos de depredação de sítios resultados de atividades antrópicas contemporâneas e ligadas a expansão socioeconômico da região.

\section{APOSIÇÃO DAS OCUPAÇÕES HUMANAS PRÉ-COLONIAIS E CONTEMPORÂNEAS DE IRANDUBA E MANAUS}

A ocupação humana pré-colonial do Amazonas recebe bastante atenção da Arqueologia dentro dos contextos de estudos sobre os primeiros registros da presença humana na Amazônia. Os vestígios arqueológicos da região são analisados a partir de três linhas de pensamento diferentes. As primeiras pesquisas na região foram executadas por Hilbert (1968) e Simões (1974), entre as décadas de 1950 e 1970 e estruturam uma sequência crono-tipológica para defender um processo de sucessivas reocupações da região por populações de origens externas. Em oposição, nos anos de 1970 e 1980, destaca-se as pesquisas de Lathrap (1970), defendendo que esse mesmo registro demonstra a ocorrência de um longo e contínuo processo de transformação social e cultural na própria região, sem influências externas.

Pesquisas Hilbert (1968) na região, identificaram sítios que tiveram seus artefatos enquadrados em quatro Fases, ou seja, enquadramento de indústria de produção de vasilhames cerâmicos de maneira a caracterizar conjuntos de artefatos tecnológica e estilisticamente similares ou diferentes para servir como marcador cultural (SCHAAN, 2007a). Embora considerado um dos grandes problemas enfrentados pela arqueologia da Amazônia, esses procedimentos ainda servem de base para classificações ou ponta pé inicial para abordagens desses materiais e sua condição de marcadores de ocupação humana no tempo e espaço.

Amparado nessa lógica, Hilbert estabelece as Fases da região a partir de atributos como formas, decoração e tipo de antiplástico, segundo os seguintes pontos: 1) Açutuba: antiplástico de caraipé, decoração com motivos incisos retilíneos, excisões sobre engobo vermelho, acanalado, apêndices zoomorfos, flanges labiais, mesiais, engobo branco e pintura policrômica. 2) Manacapuru: antiplástico de cauixi, decoração com motivos com incisões retilíneas duplas, ponteados, apêndices zoomorfos, 


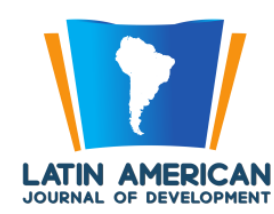

flanges labiais e engobo vermelho. 3) Paredão: antiplástico de cauixi, paredes finas, com alças e pedestais, decoradas com incisões finas, pintura em linhas finas, engobo vermelho, apliques antropomorfos estilizados (chamados de cabecinhas), geralmente associados às urnas antropomorfas. 4) Guarita: antiplástico de caraipé, bordas reforçadas, sobretudo em urnas antropomorfas. Há predominância de decoração policrômica, com motivos geométricos, pintura em áreas e linhas finas e, também, decoração acanalada, flanges mesiais, engobo vermelho e branco.

Para Hilbert, essas Fases se sucederiam no tempo, sendo parcialmente contemporâneas em alguns locais. Atualmente, a Fase Açutuba é datada para período entre os séculos III à IV AD; a Manacapuru para os séculos IV à VIII AD; a Paredão para os séculos VII à XII AD e a Guarita para os séculos IX à XII AD (HILBERT, 1968; LIMA, 2008; LIMA e NEVES, 2011; MORAES e NEVES, 2012). Boa parte desses dados foram gerados nas pesquisas do Projeto Amazônia Central (PAC), desenvolvido desde 1990 pelo Museu de Arqueologia e Etnologia da USP sobre cerca de $900 \mathrm{~km}^{2}$ de área situada entre os rios Negro e Solimões, no Amazonas (MORAES e NEVES, 2012). Se constituindo na terceira linha de abordagem da arqueologia dessa região, o PAC tem testado as hipóteses levantadas para a ocupação pré-colonial dessa área, buscando aprimorar os dados sobre complexos cerâmicos e entender sua evolução espaço-temporal.

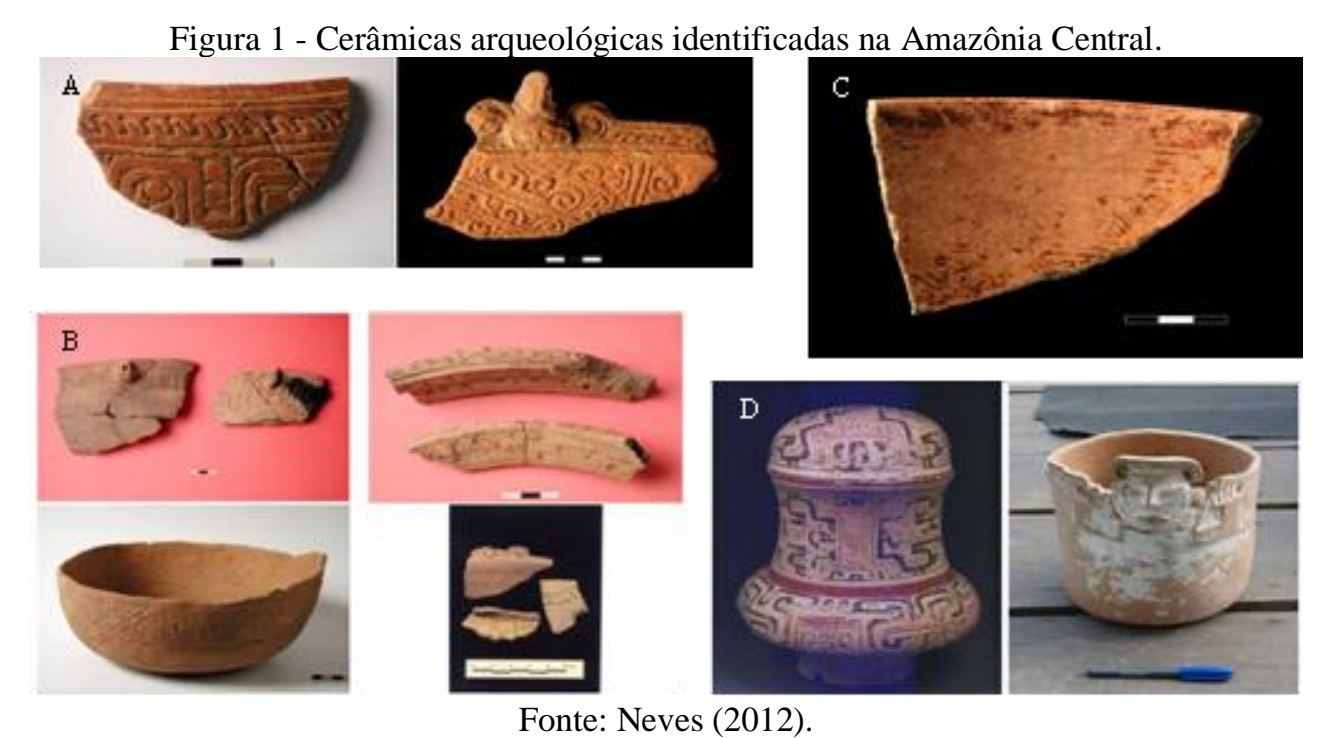

Assim, já foi produzida uma significativa literatura sobre as pesquisas realizadas na área do PAC, abordando aspectos das ocupações pré-coloniais do Amazonas, como a construção de montículos artificiais durante a Fase Paredão (MACHADO, 2005), a dinâmica das aldeias circulares (MORAES, 2010), a formação das Terras Pretas servindo como indicador do aumento da densidade demográfica e do estabelecimento de assentamentos sedentários (REBELLATO, 2007) e práticas funerárias características da região (PY-DANIEL, 2015), dentre outros aspectos culturais. 
Porém, a ocupação humana pré-colonial da área que hoje corresponde ao território do Amazonas não está apenas ligada a grupos humanos produtores de artefatos cerâmicos. Os dados gerados pelo PAC revelam que os primeiros registros de ocupação humana nessa região datam de aproximadamente 9000 A.P, com recorte temporal entre 9460 e 4500 A.P, para ocupação relacionadas a grupos nômades que tinham por base principalmente atividades de subsistência como caça, coleta de frutos e tubérculos, notadamente conhecidos como caçadores e coletores (COSTA, 2009). Esta ocupação foi identificada a partir do estudo do sítio Dona Stella e sua indústria lítica (ferramentas produzidas de rochas), este localizado na bacia hidrográfica do rio Negro, junto a demais 36 outros sítios arqueológicos.

Nas proximidades de Iranduba e Manaus, Py-Daniel et. al. (2011) detectaram a presença de pelo menos mais cinco sítios arqueológicos relacionados a esta antiga ocupação: Areal do Pequeno Igarapé, Areal do Tarumã, Bacurau, Balneária do Tarumã e Musa. As principais características desses sítios são a quase que completa ausência de vestígios cerâmicos, grande quantidade de artefatos líticos, além de estarem situados em areais.

Figura 2 - Líticos (pontas de flexa) identificadas na Amazônia Central.

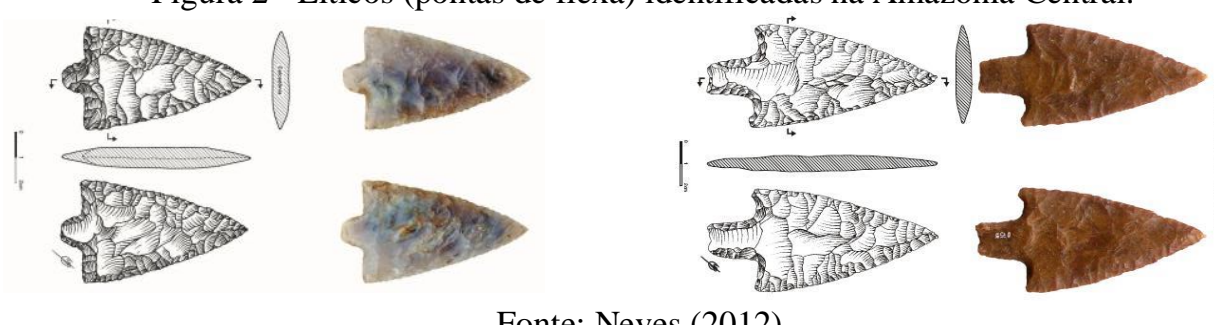

Fonte: Neves (2012).

Se no período pré-colonial, essa região já era densamente povoada por uma variedade considerável de populações, hoje, seus vestígios dividem espaços com comunidades que estruturam a sociedade amazonense contemporânea. A formação das comunidades que habitam atualmente o território do Estado do Amazonas é tributária de dois momentos marcantes de expansão socioeconômica, diretamente alinhados a dois ciclos econômicos (SOUSA, 2016). O primeiro marcado por uma urbanização sem industrialização (1870-1920), sob direção do Ciclo da Borracha e, o segundo, caracterizado por uma urbanização com industrialização (1967-2014), balizada pela atividade industrial da Zona Franca de Manaus.

Com a Borracha, o Amazonas entrou na dinâmica dos ciclos econômicos que marcaram a inserção do Brasil na condição de uma economia primário-exportadora (WEINSTEIN, 1993). O principal produto regional dessa conjuntura é a Borracha (Hévea Brasiliense), tendo o látex extraído das árvores Seringueiras como produto base. Presente nessa árvore característica da floresta amazônica, 
o látex já tinha largo uso entre os indígenas do continente americano e seus principais atributos são elasticidade e impermeabilidade. Propriedades que possibilitaram também seu largo uso industrial, especialmente no setor automobilístico (pneumáticos). Assim, a partir de meados do século XIX, com o Ciclo da Borracha, a região passou a experimentar um grande impulso em seu desenvolvimento econômico, resultando em adensamento demográfico, cujo auge ocorreu entre 1870 e 1920.

Tabela 1 - População e Taxas de crescimento do Brasil e Amazonas entre 1872 e 1920.

\begin{tabular}{|l|l|l|l|l|l|l|l|}
\hline \multirow{2}{*}{$\begin{array}{l}\text { Unidades } \\
\text { Políticas }\end{array}$} & \multicolumn{2}{|l|}{ População Censos demográficos } & \multicolumn{3}{|l|}{ Crescimento médio anual } \\
\cline { 2 - 8 } & $\mathbf{1 8 7 2}$ & $\mathbf{1 8 9 0}$ & $\mathbf{1 9 0 0}$ & $\mathbf{1 9 2 0}$ & $\begin{array}{l}\mathbf{1 8 7 2 -} \\
\mathbf{1 8 9 0}\end{array}$ & $\begin{array}{l}\mathbf{1 8 9 0 -} \\
\mathbf{1 9 0 0}\end{array}$ & $\begin{array}{l}\mathbf{1 9 0 0 -} \\
\mathbf{1 9 2 0}\end{array}$ \\
\hline Amazonas & 57.610 & 147.915 & 249.756 & 363.166 & 0,05 & 0,05 & 0,02 \\
\hline Brasil & 10.112 .061 & 14.333 .915 & 17.318 .556 & 30.635 .605 & 0,02 & 0,02 & 0,03 \\
\hline
\end{tabular}

Fonte: Sousa (2016).

Tabela 2 - População de Manaus e Percentual em relação ao das unidades da federação entre 1872 e 1920.

\begin{tabular}{|l|l|l|}
\hline Ano & Manaus & Proporção da População das capitais x UFs \\
\hline $\mathbf{1 8 7 2}$ & 29.334 & 50,9 \\
\hline $\mathbf{1 8 9 0}$ & 38.720 & 26,2 \\
\hline $\mathbf{1 9 0 0}$ & 50.300 & 20,1 \\
\hline $\mathbf{1 9 2 0}$ & 75.704 & 20,8 \\
\hline
\end{tabular}

Fonte: Adaptado de Sousa (2016).

É importante ponderar que, nesse contexto, o crescimento populacional ocorreu principalmente nos municípios do interior do Amazonas, tendo em vista a localização das Seringueiras dentro da floresta, na zona rural, sendo então as áreas para onde os trabalhadores desse ciclo econômico se dirigiram para se integrar a produção atrelada a Borracha (SOUSA, 2016). Um efeito contrário vai se dar com o ciclo econômico da Zona Franca de Manaus, este tendo como principal projeto à implantação de um polo tecnológico e industrial.

Nessa conjuntura, a migração interna no Amazonas teve fortes impactos sobre as particularidades da rede urbana do Estado. Além de pessoas vindas de outras regiões do país em busca de postos de trabalho surgidos com a Zona Franca, desde a década de 1960, houve a transferência de grandes massas de população dos municípios do interior do Estado para a sua capital, a cidade de Manaus. Assim, persistiu uma concentração de rede urbana circunscrita a uma única porção do território, tornando Manaus a urbe primaz, sem uma relação de configuração de espaços metropolitanos junto a municípios vizinhos.

Tabela 3 - População residente por situação de domicílio, Amazonas (1970 - 2010)

\begin{tabular}{|l|l|l|l|l|l|l|}
\hline \multicolumn{2}{|l|}{ População residente X Situação do domicílio } \\
\hline \multirow{2}{*}{ Ano } & Total & & Urbana & & Rural & \\
\cline { 2 - 7 } & Valor absoluto & \% & Valor absoluto & \% & Valor absoluto & $\%$ \\
\hline $\mathbf{1 9 7 0}$ & 955.203 & 100 & 406.052 & 42,51 & 549.151 & 57,49 \\
\hline
\end{tabular}




\begin{tabular}{|l|l|l|l|l|l|l|}
\hline $\mathbf{1 9 8 0}$ & 1.430 .528 & 100 & 856.716 & 59,89 & 573.812 & 40,11 \\
\hline $\mathbf{1 9 9 1}$ & 2.103 .243 & 100 & 1.502 .754 & 71,45 & 600.489 & 28,55 \\
\hline $\mathbf{2 0 0 0}$ & 2.817 .252 & 100 & 2.111 .246 & 74,94 & 706.006 & 25,06 \\
\hline $\mathbf{2 0 1 0}$ & 3.483 .985 & 100 & 2.755 .198 & 79,08 & 728.787 & 20,92 \\
\hline
\end{tabular}

Fonte: Souza (2016).

Tabela 4 - População residente por situação de domicílio, Manaus (1970 - 2010)

\begin{tabular}{|c|c|c|c|c|}
\hline \multicolumn{5}{|c|}{ População residente X Situação do domicílio } \\
\hline \multirow{2}{*}{ Ano } & \multicolumn{2}{|l|}{ Total } & \multicolumn{2}{|l|}{ Urbana } \\
\hline & Valor absoluto & $\%$ & Valor absoluto & $\%$ \\
\hline 1970 & 311.622 & 100 & 283.673 & 91,03 \\
\hline 1980 & 633.383 & 100 & 611.843 & 96,06 \\
\hline 1991 & 1.011 .501 & 100 & 1.006 .585 & 99,51 \\
\hline 2000 & 1.405 .835 & 100 & 1.396 .768 & 99,36 \\
\hline 2010 & 1.802 .014 & 100 & 1.792 .881 & 99,49 \\
\hline
\end{tabular}

Fonte: Souza (2016).

Comparando os dados demográficos entre os anos de 1872 e 2010, é possível perceber que, de uma população de 29.334 habitantes, a cidade passou a ter 1.802.014 habitantes. Conforme demonstra o mapa 1, essa expansão se deu no sentido sul - norte, partindo, portanto, da calha do rio Negro em direção à parte central do território da cidade. Além dos aspectos já referidos, segundo Alves et. al (2000), essa situação se deve ao fato de que, com o fim do Ciclo da Borracha, muitos seringueiros passaram a ocupar a calha dos grandes rios locais, dando origem às ocupações mais recentes do Estado. Até a década de 1970, a expansão demográfica da cidade de Manaus aglomerava-se nas margens dos rios nas zonas Sul, Centro-Sul, Oeste e Centro-Oeste. Mas, com a implantação da Zona Franca, a concentração da população começou a ampliar-se para as zonas Leste e Norte da cidade.

Mapa 1 - Uso e ocupação do solo da área urbana de Manaus em 1972.

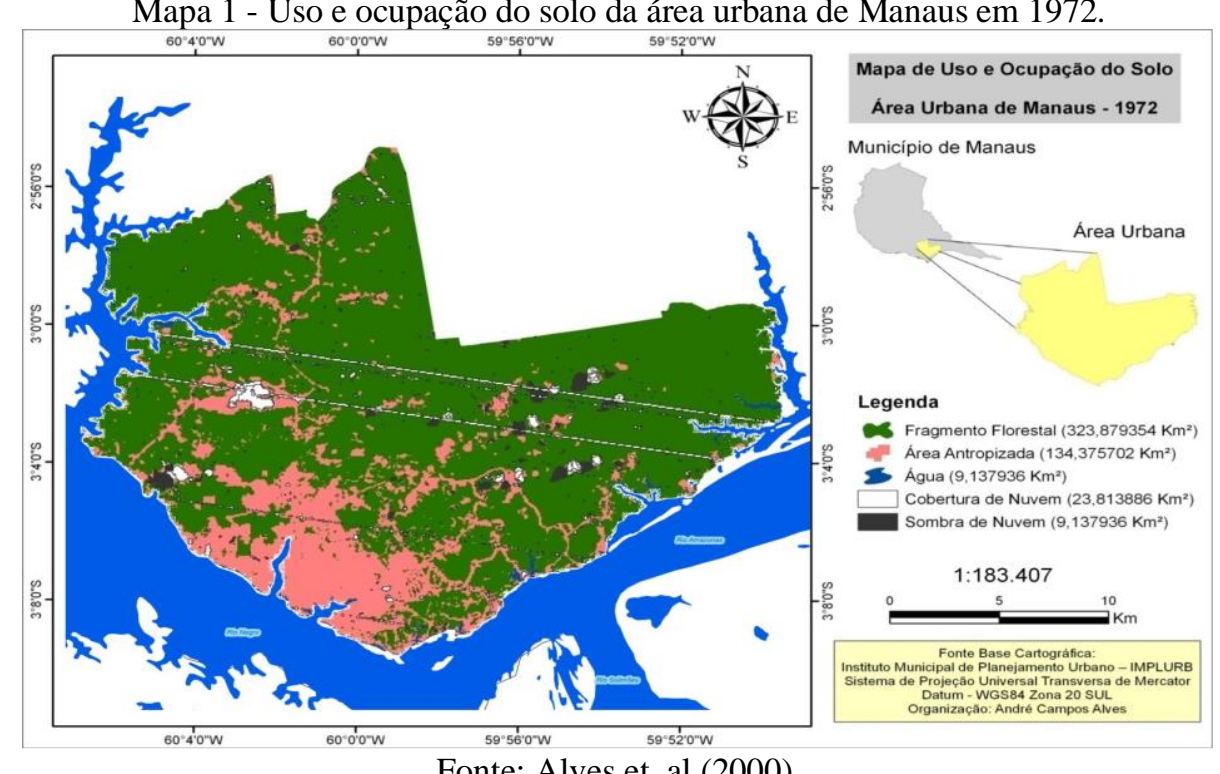

Fonte: Alves et. al (2000). 


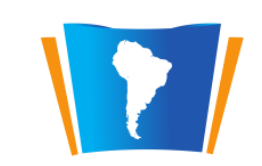

LATIN AMERICAN

Nesse período, a antropização sobre a cidade ainda era resultada dos tempos áureos da Borracha. Conforme demonstrado no mapa 1, cidade contava com $64 \%$ de sua vegetação preservada e 27\% de área antropizada. Em 2011, a área urbana de Manaus já apresentava 67\% da sua área total antropizada e os fragmentos florestais somam pouco menos de $155 \mathrm{~km}^{2}$, correspondendo a $32 \%$ da área total da cidade.

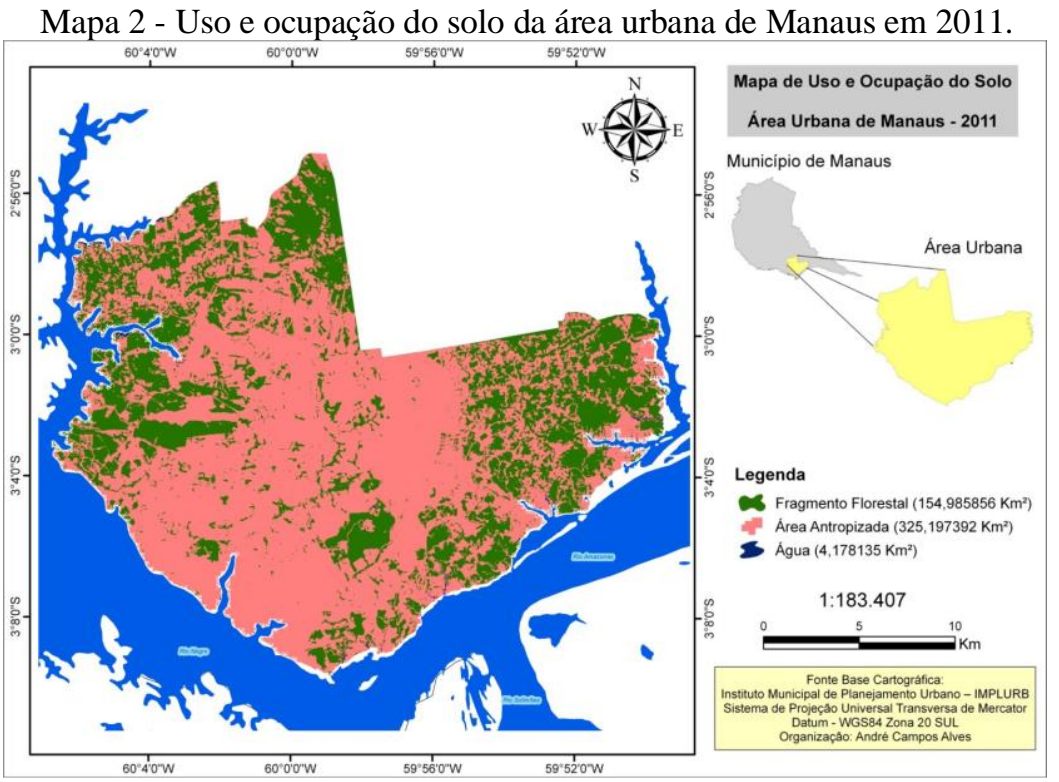

Fonte: Alves et. al (2000).

Na década de 2000, Manaus já concentrava cerca de $80 \%$ da população do Estado do Amazonas (ver tabela 3). Ao longo dos dois principais ciclos econômicos que impulsionaram a expansão socioeconômica na região, a antropização do principal espaço atingido por esses processos, a cidade de Manaus, já alcança quase $70 \%$ de sua área. Diante desse cenário, resta ponderar até que ponto essa expansão socioeconômica recente teve efeitos negativos sobre as áreas de sítios arqueológicos representativos de expansões sociais realizadas no período pré-colonial por outras populações, nesse mesmo espaço físico.

\section{CENÁRIO DO RECADASTRAMENTO DE SÍTIOS ARQUEOLÓGICOS.}

Ponderada as lógicas de salvaguarda cultural adotados no Brasil segundo seus principais instrumentos legais e que levam a programas de arqueologia como o que está em pauta; bem como o panorama de ocupação pré-colonial e as expansões socioeconômicas pós-coloniais das principais áreas de ocupação humana do que hoje constitui o território do Estado do Amazonas; chega o momento de apresentarmos os resultados práticos do convívio dessas ocupações sobre o resultado da preservação de sítios arqueológicos da região. 
O programa de recadastramento de sítios arqueológicos em Manaus e Iranduba atingiu 93 sítios constantes no CNSA do Iphan, bem como a inclusão de 7 sítios de reconhecida importância cultural pela literatura das pesquisas arqueológica da região, mas com suas informações ainda não inseridas no CNSA da forma sugerida pelo Iphan por ocasião da solicitação do programa de recadastramento. Os sítios são listados nas tabelas 5 e 6 , com numeração servindo para identificá-los no mapa $3, \log$ o a seguir.

Tabela 5 - Sítios arqueológicos alvo do programa de recadastramento em Manaus.

\section{Manaus}

1 AM-MA-1: Lages

2 AM-MA-2: Ponta Negra

3 AM-MA-4: Siderama

4 AM-MA-6: Jonasa

5 AM-MA-9: Santa Rosa

6 AM-MA-10: Terra Preta

7 AM-MA-12: Tracuá

8 AM-MA-13: Cariri

9 AM-MA-14: Tucunaré

10 AM-MA-15: Vila

11 AM-MA-16: Instituto Adventista

12 AM-MA-19: Ubim

13 AM-MA-36: UDV

14 AM-MA-69: Tucumã

15 Bela Vista

16 Estaleiro da ERAM

$17 \mathrm{Km} 36$

18 AM-MA-44: Japiim

19 Nova Cidade

20 Nova Cidade II

21 Praça Dom Pedro II

22 Porto Encontro das Águas

23 Ramal da Esperança

24 Tarumã-açu I

25 Tarumã-açu II

\begin{tabular}{ll} 
26 & Agrovila \\
27 & Alphaville \\
28 & Arara \\
29 & Areal do Pequeno Igarapé \\
30 & Areal do Tarumã \\
$\mathbf{3 1}$ & Balneário Tarumã \\
$\mathbf{3 2}$ & Barrerinha \\
$\mathbf{3 3}$ & Boa Esperança \\
$\mathbf{3 4}$ & Caiaué I \\
$\mathbf{3 5}$ & Caiaué II \\
$\mathbf{3 6}$ & Carvoaria \\
$\mathbf{3 7}$ & Carvoeiro \\
$\mathbf{3 8}$ & Comunidade do Arara \\
$\mathbf{3 9}$ & Constantino Nery \\
$\mathbf{4 0}$ & Igarapé do Jaraqui \\
$\mathbf{4 1}$ & Julião \\
$\mathbf{4 2}$ & Livramento \\
$\mathbf{4 3}$ & Marina Rio Belo \\
$\mathbf{4 4}$ & Nilton Lins \\
$\mathbf{4 5}$ & Nossa Senhora da Saúde \\
$\mathbf{4 6}$ & Nossa Senhora de Fátima \\
$\mathbf{4 7}$ & Nova Canaã \\
$\mathbf{4 8}$ & Nova Esperança \\
$\mathbf{4 9}$ & Novo Paraíso \\
$\mathbf{5 0}$ & Oliveira \\
\hline
\end{tabular}

26 Agrovila

27 Alphaville

29 Areal do Pequeno Igarapé

30 Areal do Tarumã

31 Balneário Tarumã

32 Barrerinha

33 Boa Esperança

34 Caiaué I

35 Caiaué II

36 Carvoaria

37 Carvoeiro

38 Comunidade do Arara

39 Constantino Nery

40 Igarapé do Jaraqui

1 Julião

43 Marina Rio Belo

44 Nilton Lins

Nossa Senhora da Saúde

47 Nova Canaã

50 Oliveira

51 Paredão

52 Praia da Lua

53 Praia dos Pássaros

54 Praia Dourada II

55 Praia Durada

56 Residêncial Vila Suiça

57 São Sebastião

58 Tatu

50 Terra Preta I

60 Tupé

61 Tony Medeiros

61 Daisaku Ikeda

63 Base Naval

64 Refinaria

65 Paredão I

66 Areal dos Buritis

67 Banho do Clóvis

68 Banho Familiar

69 Itaka

70 Ponta das Lages

71 Posto Aleixo

72 Ramal do Ipiranga

73 Sr. Ivan

74 UTE Mauá

75 Portal Cidade

Fonte: Adaptado de Silva et. al. (2020, 2021).

Tabela 6 - Sítios arqueológicos alvo do programa de recadastramento em Manaus.

\section{Iranduba}

$\begin{array}{ll}\mathbf{7 6} & \text { Antônio Cavalcanti } \\ \mathbf{7 7} & \text { Areal do Tokimoro } \\ \mathbf{7 8} & \text { AM-MA-11: São José } \\ \mathbf{7 9} & \text { AM-MA-5: Janauari } \\ \mathbf{8 0} & \text { Baranga } \\ \mathbf{8 1} & \text { Barbosa de Souza } \\ \mathbf{8 2} & \text { Bela Vista I } \\ \mathbf{8 3} & \text { Caldeirão } \\ \mathbf{8 4} & \text { Dona Stella }\end{array}$

$\begin{array}{ll}\text { 85 } & \text { Cleide } \\ \mathbf{8 6} & \text { Francisca Borges da Sena } \\ \mathbf{8 7} & \text { Granja do Brito } \\ \mathbf{8 8} & \text { Hatahara } \\ \mathbf{8 9} & \text { João Borges de Sena } \\ \mathbf{9 0} & \text { José Mamédio } \\ \mathbf{9 1} & \text { Lourival } \\ \mathbf{9 2} & \text { Ramal da Bichara }\end{array}$

Fonte: Adaptado de Silva et. al. (2020).

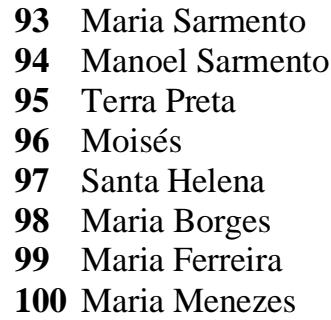

100 Maria Menezes 
Mapa 3 - Sítios arqueológicos recadastrados.

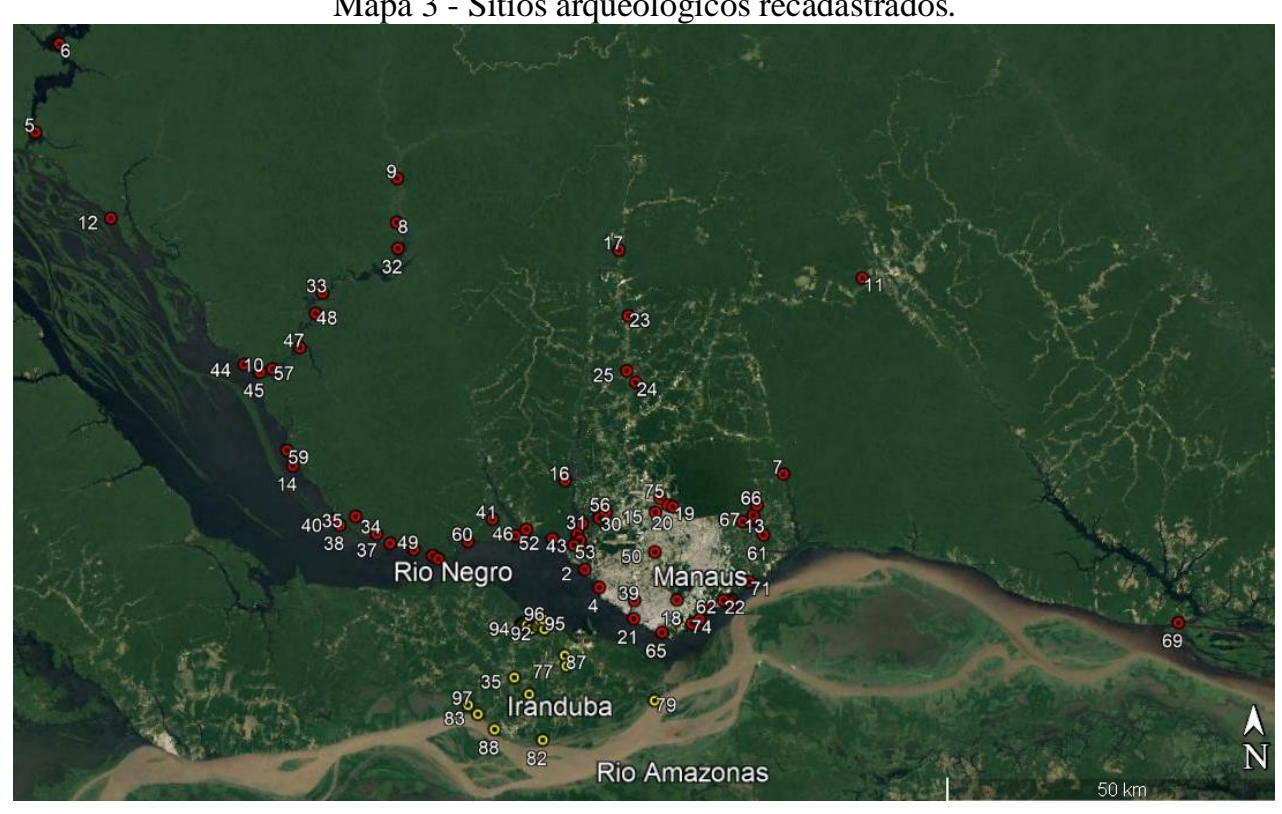

Fonte: Adaptado de Silva et. al. (2020).

Para acesso e contextualização das informações dos sítios, foi necessário a realização de levantamento bibliográfico e documental tratando das pesquisas arqueológicas e etno-históricas nos municípios de Manaus e Iranduba, permitindo a sintetização de dados sobre a arqueologia local, conforme discutido na seção anterior. Posteriormente, os sítios foram visitados visando levantamento e avaliação da atual situação de preservação ou riscos de impactos a suas áreas, bem como propor medidas para evitá-los, além da alimentação de seus dados atuais nos registros do CNSA.

Com base nesses procedimentos, foi possível identificar que, em Iranduba, há sítios em áreas rurais (Antônio Cavalcanti e Maria Sarmento); sítios em ambientes urbanos, situados em áreas habitacionais (Dona Stella e Santa Helena) e diretamente em vias públicas (Areal do Tokimoro e Granja do Brito). Além destes casos, há sítios situados as margens de braços do rio Negro, em áreas rurais (Maria Ferreira, Maria Borges, Maria Menezes, Moisés, Cleide, Lourival, João Borges de Sena, José Mamédio, Baranga, Barbosa de Souza, Manoel Sarmento e Francisca Borges da Sena) e em áreas urbanizadas (Ramal da Bichara e Terra Preta). Há, ainda, sítios nas margens do rio Amazonas em áreas urbanizadas (Caldeirão, Hatahara, Janauari, Bela Vista I e São José).

Em Manaus, foram identificados casos de sítios situados as margens do rio Negro, em área rural (Ubim, Vila, Tucumã, Nilton Lins, Terra Preta 1, Igarapé do Jaraqui, Paredão, Arara, Carvoeiro, Novo Paraíso, Carvoaria, Tatu, Tupé, Livramento e Nossa Senhora de Fátima), como também em área urbanizada (Tracuá, Estaleiro da ERAM, Praia dos Pássaros, Marina Rio Belo, Praia Dourada, Praia Dourada II, Posto Aleixo, Ponta das Lages, Daisaku Ikeda, UTE Mauá e Base Naval). Igualmente, sítios as margens de braços do rio Negro, em área rural (Cariri, Tucunaré, Santa Rosa, Terra Preta, 
Barreirinha, Boa Esperança, Nova Esperança, Nova Canãa, São Sebastião, Nossa Senhora da Saúde, Caiaué I, Caiaué II, Comunidade Arara, Julião, Agrovila, Praia da Lua e Itaka) e em área urbana (Ponta Negra, Jonasa, Praça Dom Pedro II, Siderama, Lages, Porto Encontro das Águas, Praia dos Pássaros, Praia Dourada, Praia Dourada II e Marina Rio Belo).

Há, ainda, sítios em áreas urbanas, situados em vias públicas (Km 36, Ramal da Esperança, Tarumã-açu II, Tarumã-açu I, Japiim, Portal da Cidade, Areal do Pequeno Igarapé, Areal do Tarumã, Portal da Cidade, Banho do Clovis, Ramal do Ipiranga) e em áreas habitacionais (Instituto Adventista, Bela Vista, Nova Cidade, Nova Cidade II, UDV, Tony Medeiros, Residencial Vila Suíça, Oliveira, Banho do Clóvis, Banho Familiar, Ivan, Ramal do Ipiranga, Residencial Vila Suíça, Balneário Tarumã, Areal dos Buritis, Ivan, Banho Familiar, Tony Medeiros, Refinaria, Paredão I, Constantino Nery e Oliveira).

Independentemente da localização desses sítios, foi possível a identificação de material arqueológico nas áreas da grande maioria deles, especialmente pelos impactos que elas vêm recebendo devido a ação antrópica. Mesmo nos sítios situados em ambientes rurais, portanto, estando teoricamente mais imunes a ação antrópica em larga escala, estes permanecem sujeitos a impactos. Nesses locais, foi comum encontrar áreas com vegetação descampada, em alguns casos com pessoas dispondo de moradias e exercendo atividades como agricultura de subsistência, pastoreio de gado não só com uso de espaços naturais para esses animais, como também estruturas de currais, cercas e estradas de acesso a propriedades. Situações que, consequentemente, causam destruição das áreas de sítios. Também, há episódios de sítios próximos a áreas de empreendimentos de exploração mineral e madeireiras. Nestes casos, tendo sua integridade assegurada pelos parâmetros legais de licenciamento das instalações desses empreendimentos.

Como esperado, estando situados em ambientes com mais possibilidade de ação antrópica devido a uso e ocupação do solo, sítios situados em ambientes urbanos, de fato, estão continuamente expostos a depredação. No caso em pauta, aberturas de vias públicas, como a AM-010, AM-070, BR174 e BR-319, além de vias de circulação pública (urbanas ou estradas de acesso entre áreas urbanas e rurais) ou praças e áreas de assentamentos irregulares atingiram áreas de sítios, da mesma forma que estaleiros situados nas margens dos rios que circundam as áreas urbanas, ou mesmo empreendimentos de mineração (extração de areia e argila), de olarias ou de construção civil (pontes, condomínios, subestação de energia elétrica, prédios públicos e de empresas privadas).

Ainda que, atualmente, os locais com registro de existência de sítios se encontrem expostos a essas situações de interferência antrópica, é importante referendar que alguns casos de usos de suas áreas ocorrem devido a execução de licenciamentos pertinentes junto a órgãos controladores. Consequentemente, os dados sobre as populações que ocuparam a região no período pré-colonial foram 
inseridos ou criadas condições para que se integrem a memória nacional, dada a condição legal de coleções arqueológicas como parte dos bens da União (BRASIL, 1988), conforme referendado pela Constituição de 1988.

Nos casos em que os usos das áreas de sítios não se enquadram nessa realidade, o programa de recadastramento foi importante para proposição de medidas mitigadoras de danos. Assim, os relatórios do programa (SILVA et. al, 2020, 2021) discutem situações de depredação e a necessidade de resgate arqueológico dos sítios que apresentam riscos de impacto (Vila, Janauari, Tracuá, Vila e Ubim), ou mesmo resgates emergenciais dada a já exposição de depredação de sítios por atividades antrópicas (Japiim, Tony Medeiros, Refinaria, Paredão I, Livramento, Tatu, Posto Aleixo, UTE Mauá, Carvoeira, Tupé e Julião).

Em todo caso, tomados segundo os panoramas apresentados, de fato, esses sítios arqueológicos tornam inquestionável a considerável expansão humana ao longo das margens dos rios Amazonas e Negro no período pré-colonial, bem como adentrando a parte interior da região, no território que, hoje, constitui os municípios amazonenses de Iranduba e Manaus. Embora, não seja seguro apontar relações de descendência direta entre populações pré-coloniais produtoras das ocupações dos sítios e as atuais populações dos municípios, as últimas, por sua vez, foram responsáveis por uma considerável expansão socioeconômica na região a partir dos Ciclos da Borracha e da Zona Franca, ao mesmo tempo em que passaram a ocupar as áreas dos sítios e, em alguns casos, lhes causando impacto. Com base nessa constatação, caberá aos órgãos controladores da salvaguarda desses bens arqueológicos desenvolver ações no sentido de garantir a gestão permanente e sua preservação.

\section{CONSIDERAÇÕES FINAIS? SE É BEM PÚBLICO PROTEGIDO POR LEI, O QUE MOTIVA A DEPREDAÇÃO?}

Inseridos no contexto das ações voltadas ao levantamento de sua atual condição no início da década de 2020, os sítios arqueológicos identificados na arqueologia regional da Amazonia Central, relativos à ocupação humana pré-colonial do Amazonas, remontando a períodos de recorte temporal entre 9460 e 4500 A.P, estão em relação espacial direta com a atual população de Iranduba e Manaus. Situação que muito deve a aumentos demográficos e de malha urbana decorrente de sucessivas expansões socioeconômicas desenvolvidas ao longo dos séculos XIX e XX na região.

Indo além e inserindo a realidade desses mesmos sítios no contexto jurídico que lhes conferiu a condição de bens da União, parte do patrimônio cultural brasileiro a ser salvaguardado a partir da ação direta do Estado e da sociedade, resta uma questão: se tomamos o Estado como força motriz das normas que pautam as relações sociais que sustentam nossa condição de sujeitos coletivos, o que é 
garantido, por exemplo, por leis; como explicar atos de depredação de bens culturais que essas mesmas leis editadas pelo Estado tem por fim preservar?

O panorama sobre a construção das políticas federais de salvaguarda abordado no início desse trabalho, ajuda a entender parte dessa contradição e o quanto ainda precisa ser feito nesse campo. Conforme mencionamos, até a década de 2000, a atenção dos instrumentos de salvaguarda estava concentrada sobre bens arquitetônicos relativos ao registro da colonização portuguesa no Brasil, em sua maioria associados as aspirações de uma elite social que se forma e mantem a partir desse processo histórico. Os primeiros instrumentos legais preocupados em envolver a sociedade nas discussões sobre os bens que integram a memória e identidade cultural brasileira são de 2002, caso das ações de educação patrimonial referendadas pela Portaria Iphan n. 230/2002.

Longe de negar que as percepções de cultura e patrimônio cultural se formam a partir de lógicas construídas coletivamente no bojo das práticas coletivas que sustentam as relações sociais das pessoas em contextos de vida em sociedade (GEERTZ, 2008; GONÇALVES, 2005); não, esse não é o nosso caso. Mas, se os tradicionais instrumentos de salvaguarda brasileiros referendam a missão de fomentar a preservação e valorização de bens culturais para a formação da identidade e memória nacional e, em contrapartida, durante muito tempo privilegiaram os bens resultados da ação do elemento étnico branco no processo de formação histórica do país, é natural esperar que os cidadãos não sintam ressonância cultural por bens resultados da inegável participação ativa dos elementos indígenas e negro nesse processo.

Talvez, o desenvolvimento de mais instrumentos do tipo e o avanço no uso conjunto de ações amparadas, por exemplo, no Registro, na intensificação de Programas Integrados de Educação Patrimonial, sugeridos pela IN Iphan n. 1/2015, poderão mudar essa realidade. Agora, é claro que, muito da relação entre as sociedades e os bens culturais escapam as ações de salvaguarda pautadas nos instrumentos antecessores a estes. Embora não prevendo esse tipo de ação, o programa de recadastramento de sítios, por exemplo, identificou os tão comuns casos, na Arqueologia Amazônica (BEZERRA, 2018, 2011; SCHAAN, 2007b), de pessoas que organizam suas coleções particulares de material arqueológico. O que foi observado nas comunidades adjacentes aos sítios Ubim e Vila, na comunidade de Santa Isabel, situada em uma enseada próxima da foz do rio Negro, em Manaus. Ainda no rio, mas em Iranduba, caso idêntico foi notado entre o sítio Janauari e a comunidade da Colônia Agrícola Santo Antônio.

Para as conjunturas de ações de salvaguarda, situações desse tipo demonstram a complexa relação e as particularidades da convivência mútua entre os vestígios de populações que ocuparam regiões no período pré-colonial e as que ocupam atualmente. Nesses casos, o que precisa ser ponderado é justamente até que ponto a constituição de coleções pode ou não interferir nas análises 
contextualizadas de costumes das populações pré-coloniais pela Arqueologia, posto que são dependentes da percepção da localização de sítios na paisagem, bem como da distribuição horizontal e vertical de seus artefatos no espaço e no tempo. Em todo caso, Projetos Integrados de Educação Patrimonial têm condições de contribuir não só para entender a relação dessas comunidades contemporâneas com a cultura material das populações pré-coloniais, como também encontrar maneiras de mediar essa relação com os estudos pertinentes dos vestígios arqueológicos envolvidos. 


\section{REFERÊNCIAS BIBLIOGRÁFICAS}

ALVES, André Campos; FREITAS, Ingrid Silva de; SANTOS, Mayara Queiroz dos. Análise multitemporal da expansão urbana da cidade de Manaus, Amazonas, utilizando imagens de satélite. Revista Geosaberes, Fortaleza, v. 11, p. 305-317, 2020.

BEZERRA, Márcia. Com os Cacos no Bolso: um ensaio sobre o colecionamento de artefatos arqueológicos na Amazônia Brasileira. Revista do Patrimônio Histórico e Artístico Nacional, v. 38, p. 85-101, 2018.

"As moedas dos Índios": um estudo de caso sobre os significados do patrimônio arqueológico para os moradores da Vila de Joanes, Ilha de Marajó, Brasil. Boletim do Museu Paraense Emílio Goeldi. Ciências Humanas, v. 6, p. 57-70, 2011.

BRASIL. Decreto $N^{o}$ 7.387, de 9 de dezembro de 2010. Brasília, 2010.

. Decreto $N^{o} 3.551$ de 04 de agosto de 2000. Brasília 2000.

. Constituição da República Federativa do Brasil de 1988. Brasília, 1988.

Lei $N^{o} 3.924$ de 26 de julho de 1961. Brasília, 1961.

Decreto $N^{o} 25$ de 30 de novembro de 1937. Rio de Janeiro, 1937a.

Lei $N^{o} 378$ de 13 de janeiro de 1937. Rio de Janeiro, $1937 \mathrm{~b}$.

CALDARELLI, Solange Bezerra. Problemáticas arqueológicas inéditas advindas de projetos de contrato: o caso do alto e médio vale do Paraíba paulista, UNISC, Santa Cruz do Sul. Revista do CEPA, v. 29, p. 7-33, 2005.

CONSELHO NACIONAL DO MEIO AMBIENTE - CONAMA. Resolução Conama $n^{\circ} 237$ de 19 de dezembro de 1997. Brasília, 1997.

Resolução Conama nº.1 de 23 de janeiro de 1986. Brasília, 1986.

COSTA, Fernando Walter da Silva. Arqueologia das Campinaranas do Baixo Rio Negro: Em Busca dos Pré-ceramistas da Amazônia Central. Tese de Doutorado. Programa de Pós-graduação em Arqueologia do Museu de Arqueologia e Etnologia da Universidade de São Paulo, 2009.

FUNARI, Pedro Paulo. Os desafios da destruição e conservação do património cultural no Brasil. Trabalhos de Antropologia e Etnologia, Lisboa, v. 41, n.1/2, p. 23-32, 2001.

GEERTZ, Clifford. A interpretação das culturas. Rio de Janeiro: LTC, 1. ed. 2008.

GONÇALVES, José Reginaldo. Ressonância, Materialidade e Subjetividade: as culturas como patrimônio. Horizontes Antropológicos, Porto Alegre, n. 23 (1): 15-36, 2005.

HILBERT, Peter. Archäologische Untersuchungen am Mittlern Amazonas. Berlin: Dietrich Reimer Verlag, 1968. 
INSTITUTO DO PATRIMÔNIO HISTÓRICO E ARTÍSTICO NACIONA - IPHAN. Instrução Normativa $n^{\circ} 001$ de 25 de março de 2015. Brasília, 2015.

. Portaria Iphan n. 230 de 17 de dezembro de 2002. Brasília, 2002.

LATHRAP, Donald. The Upper Amazon. London: Thames \& Hudson, 1970.

LIMA, Helena. História das Caretas: a tradição borda incisa na Amazônia Central. Tese (Doutorado em Arqueologia) - Museu de Arqueologia e Etnologia, Universidade de São Paulo, São Paulo, 2008.

LIMA, Helena; NEVES, Eduardo. Cerâmicas da Tradição Borda Incisa/Barrancóide na Amazônia Central. Revista do Museu de Arqueologia e Etnologia, n. 21, 205-230, 2011.

LIMA, Tânia Andrade. Luiz de Castro Faria: também um arqueólogo. Brasília: Memórias de Ciência e Tecnologia, Série Produção Científica Brasileira, Centro de Memória do Conselho Nacional de Desenvolvimento Científico e Tecnológico - CNPQ, 2009.

MACHADO, Juliana Salles. Montículos Artificiais na Amazônia Central: Um Estudo de Caso do Sítio Hatahara. Dissertação (Mestrado em Arqueologia) - Museu de Arqueologia e Etnologia, Universidade de São Paulo, São Paulo, 2005.

MEGGERS, Betty. Amazonia: man and culture in a counterfield paradise. Chicago: Aldine. 1971.

MORAES, Claide de Paula. Aldeias circulares na Amazônia Central. Um contraste entre fase Paredão e fase Guarita. In: PEREIRA, Edithe; GUAPINDAIA, Vera. Arqueologia Amazônica, Vol. 2 (pp. 581604). Belém: MPEG, Iphan, Secult, 2010.

MORAES, Claide de Paula; NEVES, Eduardo. O ano 1000: adensamento populacional, interação e conflito na Amazônia Central. Revista Amazônica, 4 (1), 122 -148, 2012.

NEVES, Eduardo Góes. Sob os tempos do Equinócio: oito mil anos de história na Amazônia Central (6.500 AC - 1.500 DC). Tese (Livre-Docente em Arqueologia) - Museu de Arqueologia e Etnologia, Universidade de São Paulo, 2012.

PY-DANIEL, Anne Rapp. Os contextos funerários na arqueologia da calha do rio Amazonas. Tese (Doutorado em Arqueologia) - Museu de Arqueologia e Etnologia, Universidade de São Paulo, São Paulo, 2015.

PY-DANIEL, Anne Rapp; MORAES, Claide de Paula; NEVES, Eduardo Goes; SILVA, Leandro Camilo da. Ocupações pré-ceramistas nos areais da Amazônia Central. Revista do Museu de Arqueologia e Etnologia, n. 11, 2011, pp. 43-49.

REBELLATO, Lilian. Interpretando a variabilidade cerâmica e as assinaturas químicas e físicas do solo no sítio arqueológico Hatahara-AM. Tese (Doutorado em Arqueologia) - Museu de Arqueologia e Etnologia, Universidade de São Paulo, São Paulo, 2007.

SANTOS, José Luís dos. O Que é Cultura. $3^{\text {a }}$ Ed. São Paulo: Editora Brasiliense, 1985.

SCHAAN, Denise Pahl. Uma janela para a história pré-colonial da Amazônia: Uma janela para a história pré-colonial da Amazônia: olhando além - e apesar - das fases e tradições olhando além - e 
apesar - das fases e tradições. Boletim do Museu Paraense Emílio Goeldi. Ciências Humanas, Belém, v. 2, n. 1, p. 77-89, jan-abr. 2007a.

- Múltiplas vozes, memórias e histórias: por uma gestão compartilhada do patrimônio arqueológico da Amazônia. Revista do Patrimônio Histórico e Artístico Nacional, v. 33, p. 109-135, $2007 \mathrm{~b}$.

SIMÕES, Mário. Contribuição à arqueologia dos arredores do baixo rio Negro, Amazonas. Publicações Avulsas do Museu Paraense Emilio Goeldi, n. 26, p. 165-200, 1974.

SILVA, Anna Barbara Cardoso da; MENDES, Kelton Lima Monteiro; BARBOSA, Luiz Alexandre da Silva; PEREIRA, Edvaldo. Relatório Final do Projeto de Recadastramento de Sítios Arqueológicos nos municípios de Manaus e Iranduba, no estado do Amazonas. Inside Consultoria Científica, 2020.

- Relatório Final do Projeto de Recadastramento de Sítios Arqueológicos nos municípios de Manaus e Iranduba, no estado do Amazonas. Inside Consultoria Científica, 2021.

SILVA, Benedito Walderlino de Souza da. "Nem tudo que reluz é ouro": Arqueologia Pública e tensões da gestão participativa do patrimônio arqueológico no Projeto Mutum. Caderno 4 Campos, n. 1, 2021.

Patrimônios culturais vivos em Tombamento: sentidos e práticas do patrimônio cultural para os trabalhadores do Mercado de Ferro do Ver-o-Peso. Dissertação (Mestrado em Antropologia) - Instituto de Filosofia e Ciências Humanas, Universidade Federal do Pará, Belém, 2016.

SOUSA, Norma Maria Bentes de. Urbanização do Amazonas entre o passado e presente: $a$ manutenção da primazia urbana de Manaus. Tese (Doutorado em Planejamento Urbano e Regional) Instituto de Pesquisa e Planejamento Urbano e Regional da Universidade Federal do Rio de Janeiro, Rio de Janeiro, 2016.

SERVIÇO DO PATRIMÔNIO HISTÓRICO E ARTÍSTICO NACIONAL - SPHAN. Portaria n. 07 de 01 de dezembro de 1988. Brasília, 1988.

TORRES, Heloisa Alberto. Contribuição para o estudo da proteção ao material arqueológico e etnográfico no Brasil. Revista do SPHAN, v. 1, 1938. pp. 09-20.

WEINSTEIN, Barbara. Borracha na Amazonia - Expansão e Decadência (1850-1920). HUCITEC, $1^{\mathrm{a}}$ ed. 1993. 